\title{
The prevalence of Staphylococcus aureus contamination in the ambulances and on-call emergency medical service personnel of Kashan city in Iran
}

\author{
Mohammad Paravar, Somaye Safavi, Razie Eghtesadi* ${ }^{*}$, Mahdi Mohamadzade, Mojtaba Sehat, \\ Mohammadreza Fazel, Esmaeil Fakharian, Mohammadhosein Makki, Mahzad Erami, Tayebeh Taghipor, \\ Abdolreza Dayani Najafabadi
}

Trauma Research Center, Kashan University of Medical Sciences, Kashan, Iran

\author{
Received: 8 April 2019 \\ Accepted: 11 June 2019 \\ Published online: 20 June 2019 \\ *Corresponding author: Razie \\ Eghtesadi, Trauma Reseach Center, \\ Kashan University of Medical \\ Sciences, Kashan, Iran. \\ Tel: +98-913-1631665; Email: \\ Eghtesadi-r@kaums.ac.ir \\ Competing interests: None. \\ Funding information: This study \\ was financially supported by Kashan \\ University of Medical Sciences. \\ Citation: Paravar M, Safavi S \\ Eghtesadi R, Mohamadzade \\ M, Sehat M, Fazel M, et al. The \\ prevalence of Staphylococcus aureus \\ contamination in the ambulances \\ and on-call emergency medical \\ service personnel of Kashan city in \\ Iran. Journal of Emergency Practice \\ and Trauma 2020; 6(1): 3-6. doi: \\ $10.15171 /$ jept.2019.13.
}

\begin{abstract}
Objective: Emergency medical services systems are at the first line of dealing with patients who suffer from various infections. Conducting investigations on the bacterial contamination of emergency ambulances play a crucial role to improve the occupational health of staff as well as the quality of patient care. Therefore, the aim of the present study was to investigate the presence of Staphylococcus aureus and other life treating bacteria in the urban and rural ambulances and their on-call emergency medical service personnel. Methods: This descriptive cross-sectional study was conducted on 12 front line prehospital emergency urban and rural ambulances in Kashan, Iran, in 2015. A total of 18 sites were sampled in each ambulance and from the nose of personnel. Grown colonies were confirmed based on colony morphology on mannitol salt agar plates, gram stain reaction and biochemical characteristics reactions.

Results: The $S$. aureus contamination was only isolated from the nose of on-call emergency medical service providers of 12 urban and road ambulances, while no sign of contamination was found in 18 sampling sites of these front-line ambulances. Also, further evaluation of these sampling sites revealed the contamination with coagulase-negative staphylococci in all of them and oxygen tank was introduced as the most contaminated site inside the ambulances. Moreover, the prevalence of equipment contamination was significantly higher in urban ambulances.

Conclusion: Identifying the rate of pathogens in clinical settings like the pre-hospital ambulance setting is an important issue which should be carefully considered.

Keywords: Emergency medical services, Bacterial contamination, Infection, Staphylococcus aureus
\end{abstract}

\section{Introduction}

Early laboratory and clinical investigations in 18th century demonstrated the staphylococcal illness and its role in abscess formation and sepsis. After more than a century, Staphylococcus aureus remains a life-threatening pathogen in humans. S. aureus is a Gram-positive coccus which can cause skin lesions, osteomyelitis, pneumonia, endocarditis and sepsis (1). There is no doubt that, $S$. aureus is a major cause of hospital-acquired infections and its severity is associated with the potentially infected tissues such as bloodstream, respiratory tracts and skin. Owing to multidrug-resistant strains of $S$. aureus, these infections are difficult to treat (2).

In the United States it has been estimated that annually more than 90000 deaths occur due to nosocomial infections which is the sixth leading cause of death in the
United States. For patients as well as health care providers, hospital-acquired infections are major safety concerns which can worsen the severity of diseases and increase the length of hospital stays (2). Various risk factors such as exposure to colonized patients, surgery, admission to an intensive care unit (ICU) and prior antibiotic exposure are described for $S$. aureus infection or colonization in the hospital. In addition, although $S$. aureus is a leading pathogen responsible for nosocomial infections, other bacteria may contribute to the formation of infections (3). It has been long established that $S$. aureus contamination exclusively can occur in hospitals or following the use of long-term care facilities due to the lack of strong immune system of admitted patients and also numerous catheterizations and injections (4). Up to now, there are several reports from various parts of Iran evaluating the 
epidemiology of S. aureus in Iranian hospitals (5) as a potential reservoir in the transmission of serious infections to patients. However to the best of our knowledge, there is no report to evaluate the existence of $S$. aureus in the ambulance operating system as a potential source of transmission to patients. Therefore, the aim of the present study was to investigate the presence of $S$. aureus and other life-threatening bacteria in 12 urban and rural ambulances of Kashan city and their on-call emergency medical service personnel.

\section{Methods}

This descriptive cross-sectional study was undertaken on 12 front line pre-hospital emergency ambulances inside and outside the city of Kashan in 2015. A total of 20 sites were sampled in each ambulance over a period of one month. The inclusion criteria encompassed the working ambulances in the emergency center and oncall medical service personnel on the day of sampling. In this study, samples were collected from 18 sites of ambulances including: jump bag handle, glucometer, electrocardiograph (ECG) unit handle, portable pulse oximeter outer case/finger sensor, adult blood pressure cuff, children blood pressure cuff, stretcher mattress, stethoscope, rear cabin seats, steering wheel, radio microphone, laryngoscope, oxygen tank, Ambu bag, rear cabin floor, rear cabin space, front cabin space, suction and also hand and nose of on-call emergency medical service personnel using moistened sterile cotton swabs. Following collecting the samples, the swabs were inoculated to the mannitol salt agar plates and were incubated at $37^{\circ} \mathrm{C}$ for 48 hours. This medium due to the high concentration of salt is commonly used for gram-positive bacteria such as Staphylococcus. The grown colonies from various parts of ambulances were confirmed based on colony morphology on mannitol salt agar plates, gram stain reaction, biochemical characteristics reactions including catalase, coagulase reaction and deoxyribonuclease (DNase) test. Since the rate of infection in each ambulance depends on last cleaning, this evaluation was performed randomly and the time of last equipment and ambulances cleaning, and also hand washing of the personnel were considered as effective parameters in the final analysis. Concerning the sampling, reliability and validity, an educated technician who was trained earlier under the supervision of an infectious specialist performed the tasks.

In this study, statistical analyses were performed using SPSS software (Version: 22). We used chi-square test and logistic regression for data analysis. $P<0.05$ was considered significant.

\section{Results}

In this study, among 12 evaluated ambulances, 7 cases (58.3\%) were road ambulances, while 5 of them $(41.7 \%)$ were working ambulances inside the city and no S. aureus was found in all ambulances. However, two personnel of road ambulances and one personnel in the city ambulance were positive for $S$. aureus contamination (Table 1). Also, both types of ambulances were contaminated with coagulase-negative staphylococci. Six cultures were positive Acinetobacter in which half of them belonged to city ambulances and another half belonged to road ambulances. We did not observe a significant relationship between the type of ambulances and the positive culture of this bacteria $(P=0.55)$. Also, there were 10 pseudomonas positive cultures in which $40 \%$ of them were found in city ambulances and the rest were the result of road ambulances contamination. No meaningful association was found between the ambulance type and the bacterial genus $(P=0.682)$. In our investigation, the number of ambulance missions was in the range of 10 to 300 monthly and $50 \%$ of ambulances had 30 missions in a month and the average of missions for all ambulances was 95.8 \pm 32.3 . This average for urban ambulances was $194 \pm 116.9$ times in a month, while for rural ambulances the average was $25.7 \pm 13.9$. Our findings revealed no significant association between the number of missions for both types of ambulances and the $S$. aureus contamination. Moreover, the average of contaminated equipments in all ambulances was 7.6 \pm 2.1 in which this average in urban and rural ambulances was $9.4 \pm 0.8$ and $6.4 \pm 1.9$, respectively. This difference was statistically significant $(P=0.01)$. Among 18 different sites inside the ambulances, contamination of oxygen tank was significantly higher than other sites. Also, according to the obtained data, there was a meaningful association between the number of missions and the number of contaminated subjects in the ambulances $(P=0.02)$. Table 2 depicts the prevalence of bacterial contamination of various sampling sites in the ambulances.

\section{Discussion}

Taking into account the ability of staphylococci to survive under various environmental conditions and regarding the fact that they can easily acquire many types of genetic elements which increase their resistance towards a wide range of antibiotics $(6,7)$, identifying the rate of $S$. aureus in clinical settings like the pre-hospital ambulance setting is an important issue (8). Based on the findings, the $S$. aureus contamination was only isolated from the nose of on-call emergency medical service providers of 12 urban and road ambulances of Kashan city in Iran. We did not observe a sign of contamination in 20 sampling sites of these front-line ambulances. Also, further evaluation of these sampling sites revealed that the contamination

Table 1. The prevalence of S. aureus, coagulase-negative staphylococ$\mathrm{ci}$ and other contaminations in hands and nose of emergency medical service personnel.

\begin{tabular}{lccc}
\hline Personnel & S. aureus & $\begin{array}{c}\text { Coagulase-negative } \\
\text { staphylococci }\end{array}$ & Others \\
\hline Hands & $0 \%$ & $45 \%$ & $0 \%$ \\
Nose & $12.5 \%$ & $41 \%$ & $0 \%$ \\
\hline
\end{tabular}


Table 2. The prevalence of bacterial contamination in various sampling sites of ambulances

\begin{tabular}{|c|c|c|c|c|c|c|c|c|}
\hline Sampling site & $\begin{array}{c}\text { S. } \\
\text { aureus }\end{array}$ & $\begin{array}{l}\text { Coagulase-negative } \\
\text { staphylococci }\end{array}$ & Pseudomonas & Klebsiella & Proteus & Acinetobacter & Diphtheriae & $\begin{array}{c}P \\
\text { value }\end{array}$ \\
\hline Jump bag handle & $0(0)$ & $8(66.7 \%)$ & $0(0)$ & $0(0)$ & $0(0)$ & $0(0)$ & $0(0)$ & $>0.05$ \\
\hline Glucometer & $0(0)$ & $4(33.3 \%)$ & $0(0)$ & $0(0)$ & $0(0)$ & $0(0)$ & $0(0)$ & $>0.05$ \\
\hline ECG unit handle & $0(0)$ & $0(0)$ & $0(0)$ & $0(0)$ & $0(0)$ & $0(0)$ & $0(0)$ & $>0.05$ \\
\hline $\begin{array}{l}\text { Portable pulse oximeter } \\
\text { outer case/finger sensor }\end{array}$ & $0(0)$ & $6(50 \%)$ & $0(0)$ & $0(0)$ & $0(0)$ & $0(0)$ & $0(0)$ & $>0.05$ \\
\hline $\begin{array}{l}\text { Children blood pressure } \\
\text { cuff }\end{array}$ & $0(0)$ & $4(33.3 \%)$ & $0(0)$ & $0(0)$ & $0(0)$ & $0(0)$ & $0(0)$ & $>0.05$ \\
\hline Adult blood pressure cuff & $0(0)$ & $6(50 \%)$ & $0(0)$ & $0(0)$ & $0(0)$ & $1(8.3 \%)$ & $0(0)$ & $>0.05$ \\
\hline Stretcher mattress & $0(0)$ & $1(8.3 \%)$ & $0(0)$ & $0(0)$ & $0(0)$ & $0(0)$ & $0(0)$ & $>0.05$ \\
\hline Stethoscope & $0(0)$ & $10(83.3 \%)$ & $0(0)$ & $0(0)$ & $0(0)$ & $0(0)$ & $0(0)$ & $>0.05$ \\
\hline Rear cabin seats & $0(0)$ & $2(16.7 \%)$ & $0(0)$ & $0(0)$ & $0(0)$ & $1(8.3 \%)$ & $0(0)$ & $>0.05$ \\
\hline Steering wheel & $0(0)$ & $5(41.7 \%)$ & $0(0)$ & $0(0)$ & $0(0)$ & $0(0)$ & $0(0)$ & $>0.05$ \\
\hline Radio microphone & $0(0)$ & $4(33.3 \%)$ & $0(0)$ & $0(0)$ & $0(0)$ & $1(8.3 \%)$ & $0(0)$ & $>0.05$ \\
\hline Laryngoscope & $0(0)$ & $3(25 \%)$ & $0(0)$ & $0(0)$ & $0(0)$ & $1(8.3 \%)$ & $0(0)$ & $>0.05$ \\
\hline Oxygen tank & $0(0)$ & $3(25 \%)$ & $4(33.3 \%)$ & $2(16.7 \%)$ & $2(16.7 \%)$ & $2(16.7 \%)$ & $2(16.7 \%)$ & $<0.05$ \\
\hline Ambu bag & $0(0)$ & $2(16.7 \%)$ & $0(0)$ & $0(0)$ & $0(0)$ & $0(0)$ & $0(0)$ & $>0.05$ \\
\hline Rear cabin floor & $0(0)$ & $2(16.7 \%)$ & $2(16.7 \%)$ & $0(0)$ & $0(0)$ & $0(0)$ & $0(0)$ & $>0.05$ \\
\hline Rear cabin space & $0(0)$ & $9(75 \%)$ & $0(0)$ & $0(0)$ & $0(0)$ & $0(0)$ & $0(0)$ & $>0.05$ \\
\hline Front cabin space & $0(0)$ & $7(58.3 \%)$ & $0(0)$ & $0(0)$ & $1(8.3 \%)$ & $0(0)$ & $0(0)$ & $>0.05$ \\
\hline Suction & $0(0)$ & $0(0)$ & $0(0)$ & $6(50 \%)$ & $1(8.3 \%)$ & $0(0)$ & $0(0)$ & $>0.05$ \\
\hline
\end{tabular}

with coagulase-negative staphylococci in all sites and the oxygen tank were the most contaminated sites inside the ambulances. Moreover, the prevalence of equipment contamination was significantly higher in urban ambulances. This can be the consequence of their greater number of missions.

Occupational infections among healthcare workers have been reported in various parts of the world (9-11) as well as Iran (12). Furthermore, up to now, several investigations reported the presence of $S$. aureus in ambulances and healthcare providers in which the prevalence of $S$. aureus depends on the study. In 2012, Rago et al surveyed 26 sites of 71 ambulances in Chicago-area municipalities. They found in approximately $69 \%$ of all ambulances this bacterium in which $77 \%$ of them were resistant to at least one antibiotic, while $34 \%$ showed resistance to two or more antibiotics (13). Also, Nigam and Cutter in 2003 in a pilot study reported an unacceptable level of bacterial contamination in the Welsh emergency vehicles which was reduced significantly following their cleaning and disinfection (14). In addition, in a study which was conducted in India, researchers reported the presence of S. aureus among healthcare workers with a prevalence of $13 \%$ (15) which is consistent with our findings.

Furthermore, in 2013, a cross-sectional study in the midAtlantic region evaluated the emergency medical service personnel for methicillin-resistant $S$. aureus (MRSA) nasal colonization. Their findings showed the presence of $6.4 \%$ (7 out of 110 volunteers) MRSA colonization among healthcare providers of emergency medical services (16). This finding is quite similar to the findings of Eveillard et al who reported the prevalence of $6.2 \%$ for S. aureus among hospital employees (17); This lower rate of contamination can be due to better hygiene practice among healthcare providers. Although in the present study, the rate of contamination among emergency medical service personnel is higher than some parts of the world; this prevalence is lower than the reported prevalence of $S$. aureus in the population of other Iranian hospital healthcare providers.

In hospitals, patient to patient pathogen transmission via the transiently contaminated hands of health care providers who have acquired the pathogen by handling contaminated materials or by direct patient contact is the major way of transmission. (18) This devastating condition might be worsen in ambulances due to various reasons including: 1) limited space at the back of the ambulance which is the area occupied by patients and can elevate the pathogen transmission risk in the environment; 2) the high rate of patient turnover and different patients being in the ambulance in many emergency medical services and 3) the short period of time for a thorough cleaning of the ambulance due to the busy nature of the job (19).

\section{Conclusion}

In conclusion, since emergency medical services systems are at the first line of dealing with patients who suffer from known or unknown infections, investigation into bacterial 
contamination of emergency ambulances plays a pivotal role in the control and preventing infection transmission as an effective risk management program to improve the occupational health of staff as well as the quality of patient care.

\section{Authors Contribution}

Concept and design of study, acquisition of data, analysis and interpretation of data: (Mohammad Paravar, Somaye Safavi, Razie Eghtesadi, Mahdi Mohamadzade, Mojtaba Sehat, Mohammadreza Fazel, Esmaeil Fakharian). Drafting the article or revising it critically for important intellectual content: (Mohammadhosein Makki, Mahzad Erfani, Tayebeh Taghipor, Abdolreza Dayani).

\section{Ethical issues}

This study was approved by the ethics committee of Kashan University of Medical Sciences, Kashan, Iran (\#2015-12-118). All on-call emergency medical service personnel accepted to participate in this study.

\section{References}

1. Lowy FD. Staphylococcus aureus infections. N Engl J Med 1998; 339(8): 520-32. doi: 10.1056/ nejm199808203390806.

2. Klein E, Smith DL, Laxminarayan R. Hospitalizations and deaths caused by methicillin-resistant Staphylococcus aureus, United States, 1999-2005. Emerg Infect Dis 2007; 13(12): 1840-6. doi: 10.3201/ eid1312.070629.

3. Khan HA, Baig FK, Mehboob R. Nosocomial infections: epidemiology, prevention, control and surveillance. Asian Pac J Trop Biomed 2017; 7(5): 478-82. doi: 10.1016/j.apjtb.2017.01.019.

4. Thompson RL, Cabezudo I, Wenzel RP. Epidemiology of nosocomial infections caused by methicillinresistant Staphylococcus aureus. Ann Intern Med 1982; 97(3): 309-17. doi: 10.7326/0003-4819-97-3309

5. Askari E, Soleymani F, Arianpoor A, Tabatabai SM, Amini A, Naderinasab M. Epidemiology of mecAmethicillin resistant Staphylococcus aureus (MRSA) in Iran: a systematic review and meta-analysis. Iran J Basic Med Sci 2012; 15(5): 1010-9.

6. Green BN, Johnson CD, Egan JT, Rosenthal M, Griffith EA, Evans MW. Methicillin-resistant Staphylococcus aureus: an overview for manual therapists. J Chiropr Med 2012; 11(1): 64-76. doi: 10.1016/j.jcm.2011.12.001.

7. Tong SY, Davis JS, Eichenberger E, Holland TL, Fowler VG Jr. Staphylococcus aureus infections: epidemiology, pathophysiology, clinical manifestations, and management. Clin Microbiol Rev 2015; 28(3): 60361. doi: 10.1128/cmr.00134-14.
8. O'Hara NB, Reed HJ, Afshinnekoo E, Harvin D, Caplan N, Rosen G, et al. Metagenomic characterization of ambulances across the USA. Microbiome 2017; 5(1): 125. doi: 10.1186/s40168-017-0339-6.

9. Assiri AM, Hathout HM, Anwar MM, El Dalatony MM, Abdel Kader NM. Occupational infections among health care workers in a secondary care hospital Saudi Arabia. Occup Med Health Aff 2013; 1(7): 1-4. doi: 10.4172/2329-6879.1000137.

10. Malangu N, Legothoane A. Analysis of occupational infections among health care workers in Limpopo province of South Africa. Glob J Health Sci 2012; 5(1): 44-51. doi: 10.5539/gjhs.v5n1p44.

11. Subramanian GC, Arip M, Saraswathy Subramaniam TS. Knowledge and risk perceptions of occupational infections among health-care workers in Malaysia. Saf Health Work 2017; 8(3): 246-9. doi: 10.1016/j. shaw.2016.12.007.

12. Mansury D, Ghavidel M, Ghazvini K. Latent tuberculosis infection in health care workers: review article. Tehran University Medical Journal 2018; 75(10): 708-14.

13. Rago JV, Buhs LK, Makarovaite V, Patel E, Pomeroy M, Yasmine C. Detection and analysis of Staphylococcus aureus isolates found in ambulances in the Chicago metropolitan area. Am J Infect Control 2012; 40(3): 201-5. doi: 10.1016/j.ajic.2011.08.021.

14. Nigam Y, Cutter J. A preliminary investigation into bacterial contamination of Welsh emergency ambulances. Emerg Med J 2003; 20(5): 479-82. doi: 10.1136/emj.20.5.479.

15. Vinodhkumaradithyaa A, Uma A, Shirivasan M, Ananthalakshmi I, Nallasivam P, Thirumalaikolundusubramanian P. Nasal carriage of methicillin-resistant Staphylococcus aureus among surgical unit staff. Jpn J Infect Dis 2009; 62(3): 228-9.

16. Al Amiry A, Bissell RA, Maguire BJ, Alves DW. Methicillin-resistant Staphylococcus aureus nasal colonization prevalence among emergency medical services personnel. Prehosp Disaster Med 2013; 28(4): 348-52. doi: 10.1017/s1049023x13003476.

17. Eveillard M, Martin Y, Hidri N, Boussougant Y, Joly-Guillou ML. Carriage of methicillin-resistant Staphylococcus aureus among hospital employees: prevalence, duration, and transmission to households. Infect Control Hosp Epidemiol 2004; 25(2): 114-20. doi: $10.1086 / 502360$.

18. Solberg CO. Spread of Staphylococcus aureus in hospitals: causes and prevention. Scand J Infect Dis 2000; 32(6): 587-95.

19. Roline CE, Crumpecker C, Dunn TM. Can methicillin-resistant Staphylococcus aureus be found in an ambulance fleet? Prehosp Emerg Care 2007; 11(2): 241-4. doi: 10.1080/10903120701205125. 